\title{
Nonprofit Organization Develop Social Enterprise Business Model in Taiwan: A Case Study of Taiwan's Large-Scale NPO
}

\author{
Meng-Chueh Hsu ${ }^{1} \&$ Shang-Yung Yen ${ }^{2}$ \\ ${ }^{1}$ Ph.D. Program of Business, College of Business, Feng Chia University, Taichung, Taiwan \\ ${ }^{2}$ Professor of MBA, College of Business, Feng Chia University, Taichung, Taiwan \\ Correspondence: Meng-Chueh, Hsu, Ph.D. Program of Business, College of Business, Feng Chia University, No. \\ 100, Wenhwa Rd., Seatwen, Taichung 40724, Taiwan.
}

Received: September 29, 2019

Accepted: December 12, 2019

Online Published: December 18, 2019

doi:10.5539/ibr.v13n1p169

URL: https://doi.org/10.5539/ibr.v13n1p169

\begin{abstract}
Nonprofit organizations take important roles and functions in our modern society. However, because of the fierce competitions in market and the rapid social changes, nonprofit organizations are facing the same management issues with profit making organizations, such as financial difficulties or lack of resources. In this qualitative research, in order to discuss the issue about nonprofit organization transformation from the prospective of nonprofit management and organization transformation, we interviewed a large nonprofit organization in Taiwan, analyzed the results and provided case studies. We also considered about the social enterprise model to explain the concept between nonprofit organization and social enterprise. In our conclusion, we found that when nonprofit organization transformation took a place and changed the service model into the social enterprise model, the reasons are not limited to the management needs but included to provide the more appropriate services and working approaches. Therefore, the difference between the nonprofit organization and the social enterprise is clarified through this research.
\end{abstract}

Keywords: nonprofit organization, organization transformation, social enterprise

\section{Introduction}

Since the 1980s, Taiwan's NPOs have witnessed the vigorous development. After the year of 2000, NPO's development in Taiwan has reached the top and various types of NPOs appear continuously. However, being affected by the financial crisis, recession in donation and transformation of general mood of society in recent years, the previous various kinds of small and medium-sized NPOs have to reduce the relevant service projects and programs and even cease the operation or dissolve the organization. But the resourceful large-scale NPOs abide by the aim of sustainable operation and begin to reform their service thinking model. On one hand, they voluntarily expand the financial source to relieve the financial pressure; on the other hand, they provide various service models to realize the organizational social mission for public goods.

Due to such transformation, people begin to think about the topic to transform NPOs. Faced with the pressure from the external operational environment as well as the process to provide internal service, NPOs must change their traditional method to provide relief-type social welfare service in the past. No matter whether it is aimed to satisfy the needs for organization's sustainable operation or serving the users, "transformation" is a topic that people must face from the macroscopic and microscopic perspectives. Therefore, with one Taiwan's large-scale NPO as an example, this paper discussed the key factors affecting the transformation of NPOs based on the organizational operation management and the reformation of service model.

\section{Non-Profit Organization (NPO)}

The rise of NPOs is mainly caused by 2 important factors: government failure and market failure. In the 1980s, the excessive expansion of government functions in welfare states lead to that the state cannot bear the financial loads; additionally, the bureaucracy causes lower administrative efficiency, thus the government's role of public service provider cannot provide the service to meet people's needs and even satisfy people. The failure in government function means that among the social service objects, the people who should benefit from the governmental services are excluded because the crowding out effect occurs owing to the higher exclusion cost. The failure in market function means that the private organizations cannot provide the rules where the market function can be 
fully operated in face of market competition, so that the operation of private market functions is limited.

Therefore, some organizations with the non-profit as the purpose in society undertake the partial social functions, including various social welfare and public benefit organizations, medical institutions, academic research organizations and various foundations. Such kind of organization is collectively called "Non-Profit Organization" or "The Third Sector"). Such kind of organization has the characteristics of not distributing earnings, and consumers can recognize the nature that NPOs do not take the pursuit of profit as the purpose even if they cannot judge and assess the service quality or quantity accurately. Therefore, compared with the profit organizations or private sectors, NPOs are trustworthy because they will not lower the quality to pursue the organizational benefits.

Actually, NPOs have been existing for a long time. In the past, they did not attract the great attention from the society due to the smaller size and influence. However, the current NPOs have significantly intervened in public affairs and influenced people's life deeply and significantly. In Taiwan, since the 1980s, the activities of NPOs have gradually seen the prosperous development due to the lifting of political martial law and development of plural society and meanwhile NPOs have rid themselves of the traditional role to merely award the scholarship, subsidize researches or engage in charity work. Now, NPOs directly involve in various social important issues and they play the role which cannot be overlooked whether in the process of policy planning, policy legalization or policy implementation. Thus, government should make good use of the resources of NPOs and plan the specific and efficient overall schemes where NPOs can participate in the service, so as to dig out and collect the folk manpower, materials and financial resources and engage in the donation and establishment of public affairs. Meanwhile, positive interaction model between governmental sectors and NPOs is developed to promote that they can support and complement each other and co-create social well-being.

The management of NPOs relies on the cohesion and guidance of "mission", instead of being driven by "profit motive". They obtain the support from the supporting groups in various aspects through the "mission" which can reflect social needs. Peter Drucker believes, "the purpose of fund raising is to support NPOs to realize their mission smoothly, rather than placing the mission under the fundraising". The most important feature of NPO lies in the mission and it represents the organizational responsibility, publicity and belief and meanwhile as the action policy to guide NPO, it represents the existence value of NPO.

The biggest difference between NPO and profit organization lies in that NPO takes the mission as the purpose and all the organizational behaviors are based on the mission guidance. "Mission" is the purpose of setup and existence of organizations and it is highly crucial to NPOs and also has the specific guiding role on organizational decision and direction. Therefore, the specific organizational mission can make NPOs have the clear consensus on "to whom we should provide service and what needs we should satisfy" during the decision making or action taking and meanwhile the consistency principle can also be generated in the priority of resource allocation. On the other hand, it makes the organizations know for whom they work and contributors know for whom they contribute to. Thus, employees can have the work focus and striving direction for service work. In conclusion, the rise and development of NPO is the mutual combination of internal and external factors.

In recent years, the various external factors have been changing rapidly in Taiwan and NPOs have faced with the problems such as government regulations, financial pressure, general mood of society, etc., which will be bound to affect the providing of internal service model; the contributors attach more importance to the expenses and benefits of various service models and they hope the organizations must make use of the social resources more efficiently and challenge the feature of "non-profit". From then on, they begin to believe that NPOs must have the ability to broaden the financial source independently. Thus, NPO was proposed since the beginning of the concept of social enterprise originated from European society (OECD, 1999) and it mainly aims to help to solve social problems by means of commercial profit making.

\section{Social Enterprise}

\subsection{Social Enterprise: The Blended Value Proposition}

Based on the past findings, the concept of social enterprise is developed from NPO and it gradually develops out its clear definition (Kerlin, 2006). According to Alter (2007), the difference between social enterprise and enterprise lies in "the difference in organizational goal"; social enterprise pursues the realization of "social goal", while the general profit-making enterprise pursues the obtainment of "economic goal". However, in the diverse society, how many proportions should be occupied by the importance of "social goal" in an enterprise so that this enterprise can be called social enterprise? According to Figure 1, the difference between social enterprise and traditional profit-making enterprise can be defined clearly, but in the degree, the judgment criteria cannot be accurately indicated. 


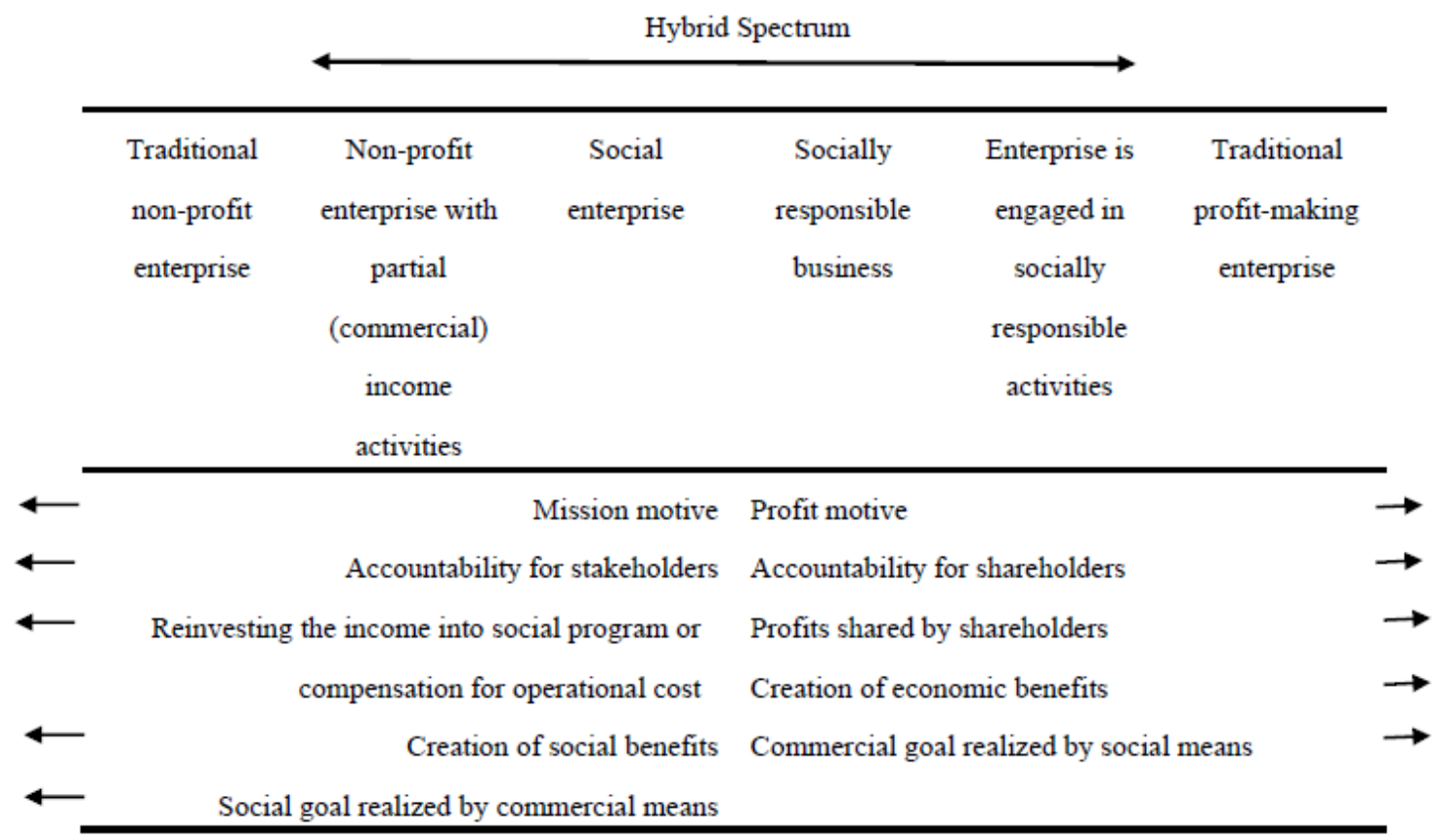

Figure 1. Hybrid Spectrum for Social Enterprise (Alter, 2007)

Jed Emerson (2003) put forward a set of "The Blended Value Proposition" to try to explain that there is no mutual conflict between "social goal" and "economic goal". In the blended value proposition advocated by him, it is assumed that the results generated by organizational action simultaneously contain the realization of economic, social and environmental goal, namely these 3 values can be created at the same time and what the organization pursues is to maximize the output of integrative value (Emerson, 2003). In other words, Emerson's blended value proposition believes that organizational action output results adopt the overall proposition and different attributes of values can exist at the same time, so different attributes of values should not be assessed in segments and blocks but being assessed as a whole.

The blended value proposition has really provided a set of new narration orientation for the argument on the importance of "social goal and economic goal", but in practical experience, the problems of NPO and social enterprise remain unsolved. Its biggest problem lies in that if NPO has no core value or the core value is unclear, the organization will lose its purpose and mission. As for NPOs, "trustworthiness" is a very important social marker. If it is considered that the economic goal of organizational action is higher than social goal, it is very difficult to be accepted by the public and meanwhile the governmental related land tax and other levies preference will be lost (Lu, 2008). As a result, it is a quite important issue about how to integrate the "social mission" of NPO and "economic goal" of social enterprise in practice.

\subsection{Social Enterprise Model Types}

Taiwan's social enterprise types are quite diversified, which also reflects Taiwan's expectation to solve the social problems. Social enterprises are not merely limited to governmental sectors or NPOs and they begin to develop towards various models. Professor Yu-yuan Kuan (2007) proposed the following 5 analysis types for Taiwan's social enterprise types:

1) Positive employment-stimulation-type social enterprise: being characterized by "work integration", this kind of social enterprise pays great attention to the vulnerable groups (especially the people with disabilities) excluded by the society and they provide work to these people and make them enter the labor market through integration. This kind of social enterprises is mostly operated by NPO belonging to the field of the disabled, and they set up workshop or sheltered workshop to provide vocational training and employment opportunity. Such kind of social enterprise has been equipped with the higher commercial orientation in operational methods, but to some degree, it still relies on the governmental support. 
2) Local community-development-type social enterprise: such kind of social enterprise is produced from the concept of community development or community construction and its main purpose is to drive the development of community industry and improve community economy. For instance, after the 921 earthquake, the Long-Yan-Lin welfare association in Zhongliao Town, Nantou County led the traditional rural community to make use of the agricultural products produced by themselves to create the outstanding community features and economic achievements.

3) Service-providing and product-sales-type social enterprise: such kind of social enterprise emphasizes user's pay concept and purchase-based service concept. They can make profits from the service models no matter whether it is negative use by paying or positive purchase service. The revenue creation is valued by such kind of social enterprise, emphasizing that financial autonomy and stability is the important factor to realize organizational mission.

4) Public benefit and venture capital independent-enterprise-type social enterprise: in Taiwan, the number of such kind of social enterprise is far smaller than that of other types. It is a company with development potential and rapid growth which is invested and set up by one enterprise or several enterprises and even NPOs; after the profit making through commercial behavior and enterprise management, it is assigned to NPOs or engaged in social affairs for public good. Such kind of social enterprise is the same as the general profit enterprise and they only differ in profit distribution.

5) Social-cooperative-type social enterprise: such kind of social enterprise is originated from Europe's social problem solving method and it is expected to solve the social problems through the power of the public, such as labor cooperative, farmer cooperative, consumer cooperative, etc. But according to Taiwan's laws, they are regarded as enterprise organizations and must abide by relevant legal regulations. The biggest feature lies in profit distribution, which focuses on all the cooperative members instead of the minority directors or bosses.

\section{Transformation of NPO and Social Enterprise Model}

According to organizational growth model of Greiner (1972) (Figure 2), it can be known that the organizations have to go through 5 sequential growth phases during the evolutionary process. In order to evolve to the next phase, organizations must manage and solve various operational crises and problems successfully. Therefore, both profit enterprises and NPOs have to face the transformation issue brought by organizational growth. Whether the NPO's challenge for social environment in different growth phases produces different solutions and whether it can continuously adhere to organizational mission are worthwhile to be used to review the task in each stage of NPO development.

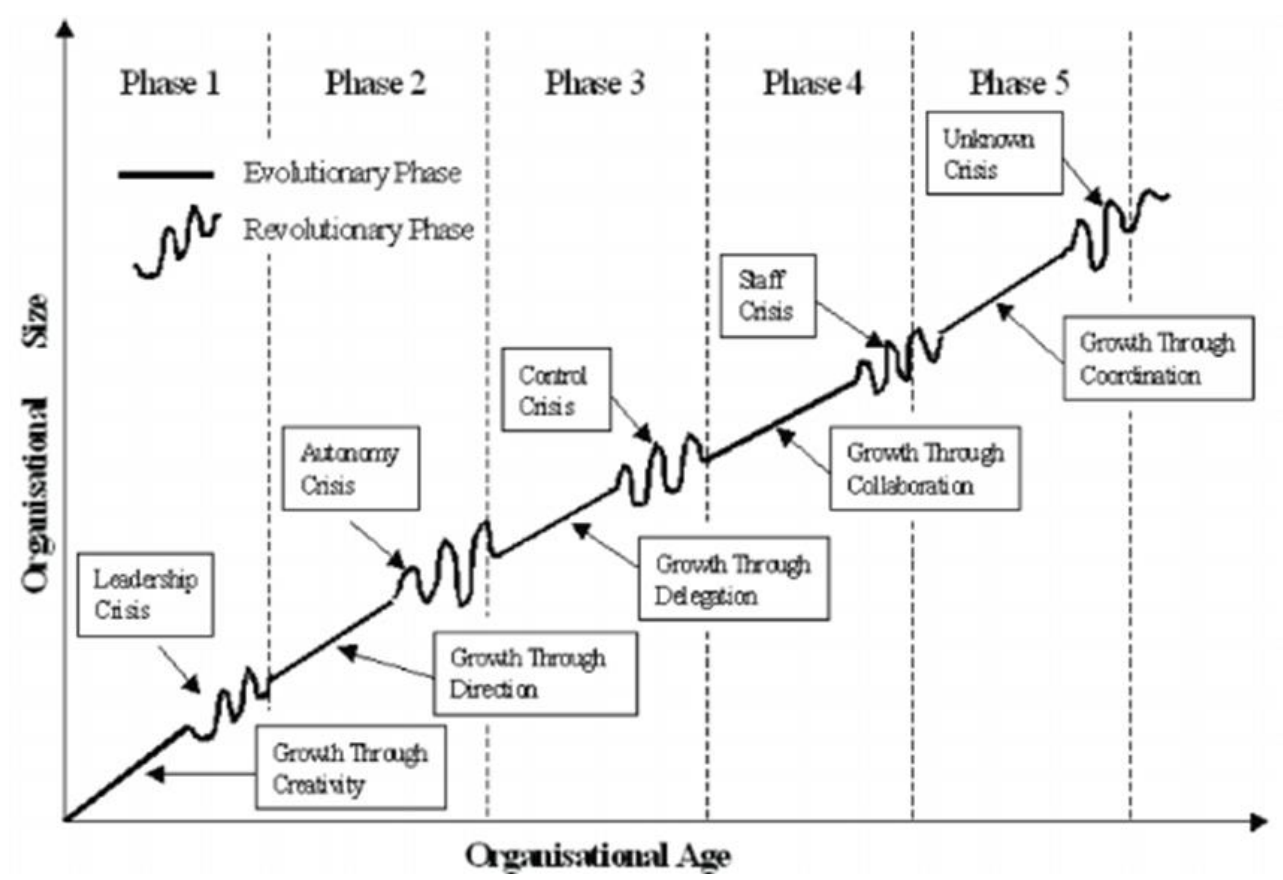

Figure 2. Organizational Growth Model (Greiner, 1972) 
On the other hand, Greenberg argued that no enterprise or organization can develop without the topic of "organizational change", because the constantly changing internal and external environment and the constantly integrating and changing organizational resources will bring various opportunities and challenges to organizations, it is necessary to pay close attention to the needs of organizational change at any time. In other words, organizational change is to adapt to the changes in internal and external environment, aiming at improving organizations' constitution and service efficiency. Hence, Lewin (1951) proposed the theory of organizational change and explained that the process of organizational change is unfreezing, conversion and refreezing.

Among them, "unfreezing" refers to stimulating organizations to change or abandon the original attitudes and to dissolve the factors causing such attitudes or behaviors. By instilling some new ideas and minimizing the attitude of "sticking to old ideas", organizations can be encouraged to accept new ideas. "Conversion" is to make organizations different from what they used to be by accepting various stimulations, which may be caused by imitations. In the process of change, organizations can be finalized by imitating new organizational behaviors, patterns and models. In the end, "refreezing" refers to the process of preserving new organizational behaviors and models after expecting organizations to abandon original old behaviors and models. The process of overall organizational change can be summarized as below (Figure 3).

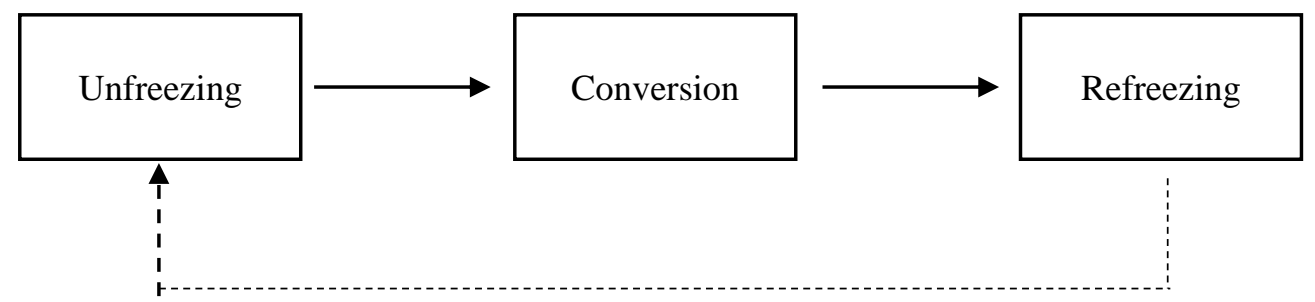

Figure 3. Process of organizational change (Lewin, 1951)

Faced with the simultaneous occurrence of "globalization" and "localization" issues, NPOs need to make a constant adjustment and change to deal with the challenge brought by environmental changes and it often faces the threat of uncertain financial source under the challenge of welfare state crisis. Therefore, driven by organizational purpose and mission, NPOs begin to seek for the possibility of self-sufficiency in finance and intervene in profit-making market and the concept of social enterprise emerges at the right moment. In other words, it is the new model with the combination of 2 sectors: enterprise and society.

Also for this reason, the background and cause for the occurrence of social enterprise is closely related to governmental financial source crisis, economic recession and other time and space factors. In the 1970s, the long-term rapid expansion in public expenditure and the decline in economic growth by the welfare system in European countries cause the government deficit to increase year by year and cause the financial crisis to European and American countries. Besides, due to the increasingly serious unemployment problems, the European governments reform the relevant labor and employment market. The failure in welfare states enables many countries to adopt outsourcing method to ease financial pressure and the decentralized practice makes the welfare closer to the needs of the public. Especially in the United States, such outsourcing method provides the new space for non-profit sectors. Under such atmosphere, in addition to the growth in non-profit sectors, the "social enterprise" which is different from the traditional non-profit sectors emerges (Cheng, 2005).

After the reasons for the transformation of NPOs or engagement in social enterprise model are summarized, approximately the following 5 factors can be concluded (Kuan, 2007):

1) In response to the social demands: the establishment of most Taiwan's NPOs aims to serve the vulnerable groups, so as to make up for insufficiency in the functions of government (public sectors) or general profit-making enterprise (private sectors). During the process of providing service, it is obvious that the traditional relief-based service is insufficient and the new welfare services such as interactivity, fishing pole-based service model arise.

2) Pursuit for the financial stability and autonomy: the social resources are limited, especially the financial resources. Since the 1980s, Taiwan's NPOs have grown rapidly, but due to the limited social resources (including governmental and civil resources), NPOs have to actively seek for new way out for financial autonomy. 
3) Promotion of social welfare privatization and purchase-based service: at the end of 1980s, Taiwan government began to promote the policy of social welfare privatization to save the cost and make up for the deficiency in governmental social workforce. On the other hand, the concept of user fee gradually form, causing purchase-based welfare service to emerge, such as long-term caring, home service, day care for the aged, etc.

4) Induction of governmental policy and budget subsidy: since the end of the 1990s, governmental sectors have successively promoted the policies of "welfare industrialization" to relieve the impact of unemployment on the society. Thus, many NPOs began to add the profit-making commercial behavior in the routine operational plan, like the appearance of "setup of sheltered workshop for the disabled as well as funding methods".

5) Enterprise values the practice of social responsibility: after the 921 earthquake, Taiwan's enterprise began to attach importance to the participation in social responsibility and realized that enterprise's operation must combine social justice and responsibility. The long-term and systematic participation in social public benefit activities not only has the social function, but also it is helpful to enterprise image. Therefore, "Corporate Social Responsibility" or "Corporate Philanthropy" is gradually valued.

In conclusion, social enterprise refers to obtaining the funds required by the operation of NPOs through commercial profit making method to realize organizational social mission or purpose (Lu, 2008). From the perspective of system, social enterprise can also be called the plan or organization managed by social entrepreneurs to achieve the citizen's purpose through knowledge and skill of commercial operation; during this process, the two issues of "society" and "enterprise" are the directions from which "social enterprise model" cannot deviate.

\section{Discussion on Business Model}

The term "business model" first appeared around 1950s and gradually became an important topic in management in 1970s (Konczal, 1975). It is also known as management model, enterprise model, commercial model or operation model. In practice, an innovative business model can not only assist enterprises in understanding the market demands and accurately delivers values to make profits, but also bring the changes in industrial patterns, which is why this study starts with business model, hoping to help non-profit organizations to find another operational opportunity in the future.

Based on the definitions of business model by various scholars, Brandenburger \& Stuart (1996) argued that a business model is a way for enterprises to create values and make profits under the consideration of reasonable costs. Lewis (2000) emphasized that a business model is a way for business organizations to describe how to create and sustain profits. Davis \& Spekman (2003) indicated that a business model is to explain the activities enterprises engage in to provide values to customers or potential customers, from which the logic of operational strategy thinking and value creation expressed by enterprises can be understood. Finally, Hamel (2000) proposed the theoretical framework of business model from the perspective of strategic management and argued that innovation is a skill which can help business organizations to think about current models with new perspectives and thus develop innovative models.

The business model structure (as shown in Figure 4) proposed by Hamel (2000) is composed of four major elements, including "core strategy", "strategic resources", "customer interface" and "value network", by cooperating with each other, and the correlation among all elements is strengthened based on 3 connection methods: "connecting customer interface with core strategy by customer benefit", "connecting enterprises' core strategy with strategic resources by structure" and "connecting strategic resources with value network by company boundary". Finally, the 4 business elements including efficiency, uniqueness, fitness and profit boosters are used to evaluate whether enterprises are profitable. The above discussion shows that, the business model structure proposed by Hamel focuses on internal factors of enterprises and is more suitable for large business organizations to use for internal transformation. 


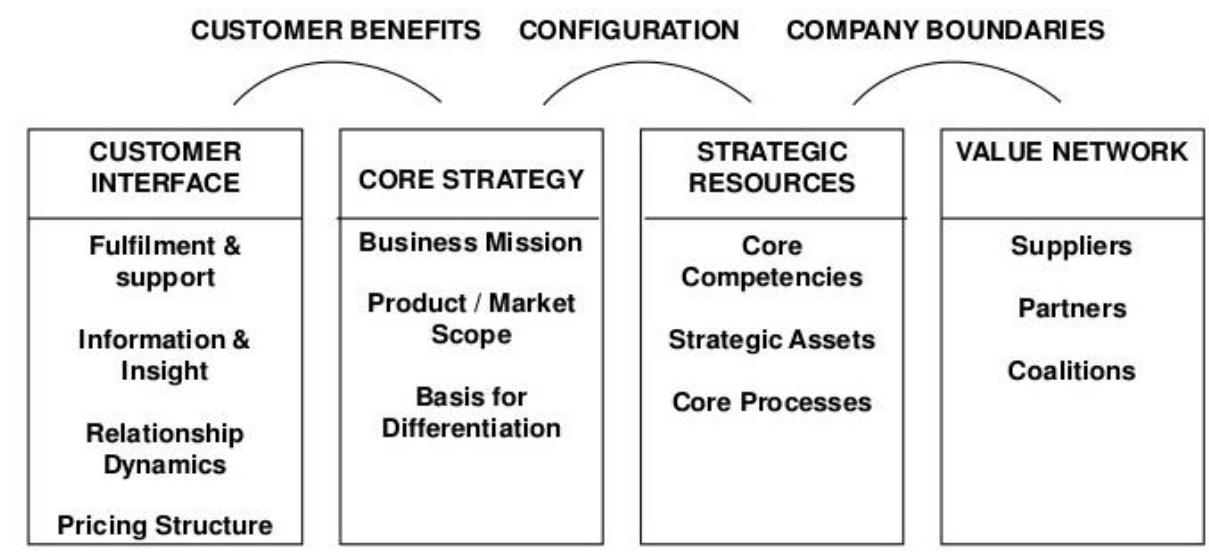

EFFICIENT / UNIQUE / FIT / PROFIT BOOSTERS

Figure 4. Hamel's business model structure (Hamel, 2000)

In addition, Osterwalder \& Pigneur (2010) integrated the basis of various concepts of business model, and argued that the main concept of business model is composed of 9 interlinked and interacted business elements and describes the methods of an organization to create, deliver and capture values. Therefore, they proposed "Business Model Canvas", including "value propositions", "key resources", "key activities", "key partners", "customer relationships", "channels", "target customers", "revenue streams" and "cost structure" (Figure 5), and showed the business model structure and the connection among all business elements in a nine-rectangle-grid way, so as to respond to the rapidly changing business environment. The key purpose is, through a simple and fast business model structure, to describe the value propositions, to arouse the interests of target customers, to connect channels, to establish the needed key resources and activities and to create an innovative business model.

\begin{tabular}{|c|c|c|c|c|}
\hline \multirow{2}{*}{$\begin{array}{l}\text { Partner } \\
\text { Network }\end{array}$} & Key Activities & \multirow{2}{*}{$\begin{array}{c}\text { Value } \\
\text { Propositions }\end{array}$} & $\begin{array}{c}\text { Customer } \\
\text { Relationships }\end{array}$ & \multirow{2}{*}{$\begin{array}{l}\text { Customer } \\
\text { Segments }\end{array}$} \\
\hline & Key Resources & & Channels & \\
\hline \multicolumn{2}{|c|}{ Cost Structure } & & \multicolumn{2}{|c|}{ Revenue Streams } \\
\hline
\end{tabular}

Figure 5. Osterwalder \& Pigneur (2010): Business Model Canvas

From the above discussion, this study argues that a business model is the activities and strategies carried out by an enterprise to continue to make profits and contains the core values and innovative thinking to be expressed by the enterprise. On the other hand, non-profit organizations can use the business model structure proposed by Hamel to evaluate whether there is a phenomenon of stagnation in their own organizations, and then to propose corresponding strategies and thinking as responses. Moreover, the Business Model Canvas of Osterwalder \& Pigneur was used to examine whether there is any opportunity to create and sustain profits in the future business plans, so as to assist non-profit organizations in organizational change and facing future changes and challenges. This is also one of the important purposes of this study. 


\section{Study Method and Case Introduction}

\subsection{Qualitative Method}

Qualitative study was the main method adopted in this study, and case study and in-depth interview were used to collect first-hand data through in-depth case interview with semi-structured questionnaires. The case study method makes great contributions to the study on individuals, organizations, the society or politics. Hence, the case study method is widely used in the disciplines such as psychology, sociology, political science, enterprise management, social work and education.

As one of the common methods for data collection in qualitative study, in-depth interviews are to use the question-and-answer and oral conversation with the study subjects to discuss and exchange ideas and opinions, so as to collect the first-hand data as the original sources for study and analysis. In this study, based on the topics and needs, semi-structured questionnaires were used for the interviews with senior managers and social enterprise programs' leaders of the study subject. Through in-depth interviews and interactions, the motivations and reasons for organizational transformation of the study subject were collected and the current business models of the social enterprise were discussed to make the conclusions of this study. Hence, the design of the "semi-structured questionnaires" required by the interviews is based on the needs of this study, and a total of 20 questions are developed, classified into 4 categories and organized in the following table.

\begin{tabular}{|c|c|}
\hline Category & Topic \\
\hline $\begin{array}{l}\text { Basic organizational } \\
\text { information }\end{array}$ & $\begin{array}{ll}\text { 1. } & \text { Organization introduction and services. } \\
\text { 2. } & \text { Company's capital scale and number of employees. } \\
\text { 3. } & \text { Company registration and form. } \\
\text { 4. } & \text { Social enterprise business mode. } \\
\text { 5. } & \text { Relationship between the business model and the organization. }\end{array}$ \\
\hline $\begin{array}{l}\text { Reasons for organizational } \\
\text { transformation }\end{array}$ & $\begin{array}{l}\text { 1. Why start developing a business model? } \\
\text { 2. } \\
\text { 3. } \\
\text { 4hy purpose / mission / goal } \\
\text { 5. Source / flow / planning of funds. } \\
\text { Future human resources planning: constitution of employee, abilities \& } \\
\text { attitudes, human resource system. }\end{array}$ \\
\hline $\begin{array}{c}\text { Social enterprise business } \\
\text { model }\end{array}$ & $\begin{array}{l}\text { 1. Is the current business model working well? } \\
\text { 2. Current management conditions: business volume. } \\
\text { 3. Current management conditions: risks / difficulties / advantages / } \\
\text { disadvantages. } \\
\text { 4. Upstream and downstream partners, supply chains, stakeholders. } \\
\text { 5. Disposal ways for profits or losses. }\end{array}$ \\
\hline Predictive suggestions & $\begin{array}{l}\text { 1. Is there any plan to increase stores or expand scale? } \\
\text { 2. Is there a stop-loss point? } \\
\text { 3. Is there an exit mechanism? } \\
\text { 4. Suggestions for the latecomers. } \\
\text { 5. Is there any thought? }\end{array}$ \\
\hline
\end{tabular}

This study focused on the discussion of "social enterprise business model" and "organizational transformation", hoping to understand the reasons why Taiwan's non-profit organizations decide to transform the organization after thinking about the internal and external environment factors through the development process of the study subject, and analyzed the social enterprise business model developed after organizational transformation, expecting to benefit the future latecomers.

\subsection{Social Enterprise Business Model for This Case Study}

The case in this research was Taiwan's largest social welfare-oriented NPO, and its service items include "assistance with poor family" and "protection of child and adolescent", with about 1,600 employees. They are distributed in every county and city in Taiwan and the yearly expenditure is about NTD 5.5 billion. In recent years, the service areas have been expanded to international society. In addition to Taiwan, there are other 8 international strongholds providing the relevant social service items.

This case has started the model of social enterprise concept since the end of 2007. Based on the spirit of "innovate the way to get rid of poverty, exploit public welfare establishments, cultivate the advantages of the case, expand self-reliance opportunity", the implementation-oriented job training course is planned to provide the practice-oriented training course in line with local feature and case speciality, so that the participants can 
constantly try to research and develop the products in the course and improve the quality through revision to meet the market requirement. After many years of exploration and adjustment, three different kinds business model of social enterprise operational methods are developed and they are introduced as below:

1) "Commodity supply business model":

"Commodity supply business model" focuses on producing commodity and providing service, the products are produced and developed (or the manpower services are provided like cleaning) by a group of supported family members accepting job training, and the organizations support marketing, product consulting and other operational assistance, so that the cases can learn from mutual help and gain the income. The developed commodity or labor service is also related to the local features of supported families or the traits of scheme developers. Since 2014, nearly 80 supported mothers and young people have been able to make a living and become independent and they have also set up the local workshop to continuously produce commodities and transform them into local tourism industry. In this model, the supported objects participating in the scheme focus on producing products or providing service. It is expected that they can become independent and get rid of the poverty after they have learned a professional skill. In addition to the tasks of planning the skill training and helping with product development and training, they also shoulder the responsibility of product marketing. Therefore, the organizations set up the network sales platform to assist with the sales and purchase of commodity production and employ the full-time employees to assist with the marketing. It is hoped that it can help to serve the case.

In this model, the supported targets who participated in the program mainly engaged in product production and labor service supply and expected to be able to lift themselves out of poverty after learning skills, therefore, it was also responsible for product marketing in addition to skill training and the task of assisting in product development and design. On this basis, the study subject established an online sales platform (e-business), expecting to assist in product sales and procurement through the sales model of e-business, and employed professionals to assist in product planning and marketing, hoping to be helpful to service cases.

2) "Cooperative store operation business model":

"Cooperative store operation business model" mainly focuses on the method of setting up the shop to sell commodity or provide the meals and meanwhile the full-time or part-time work opportunity is provided to the parents or adolescents of the supported family to stabilize the employment. At present, there are totally 2 shop operation type social enterprises and they have cooperated with Taiwan's famous convenience store "FamilyMart". In combination with the management system and operational model of FamilyMart company, the convenience store was set up in one Taiwan's famous technology company respectively in 2009 and 2013. In this cooperative model, FamilyMart is responsible for providing the channel, personnel training and know how about shop operation, the technology company is responsible for providing water and electricity and site, and organization is responsible for providing employment manpower and job training, so that the serving case can have the employment opportunity and is responsible for the follow-up shop operation. Meanwhile, the salary is adjusted gradually through social worker's support and company as well as employ's evaluation system to encourage employees to pursue for future studies. The largest feature of shop operation is to provide the higher salary and the elastic working hours. Thus, the adolescents' schoolwork and women's family caring responsibility can be considered at the same time. Since the foundation of "FamilyMart", each shop provides about 8-10 stable employment opportunities to the parents or adolescent of supported families and meanwhile the serving case is trained to be promoted to management post and to increase its vocational skills. In terms of operation, monthly turnover (about NTD 300,000) is quite stable and the yearly earnings are about NTD 1.2million after the deduction of related operational costs.

3) "Self-catering service business model":

"Self-catering service business model" is the one that the study object began to plan at the end of 2018, expecting to create profits through "catering services", with the original intention of expecting to try to develop a social enterprise business model of "full commercial operation". Therefore, in the early stage of planning, commercial teams were introduced for startup coaching, including the professional chefs and the counselors on strategic planning, brand marketing and sales reception, hoping to offer assistance for non-profit organizations having insufficient understanding on business environment and 
inadequate professional abilities in catering. After planning, discussion and analysis of the market in the region, the main business item of the restaurant was "food delivery" with "eat-in meals". However, in consideration of only about 15 seats inside, "food delivery" was the main business item. In this model, it was planned to invest NT 5 million for opening preparation and early operation in the first place, hoping to reach the break-even 6 months after the opening, to recover the capital after 12 to 18 months and to make profits after 24 months. After nearly a year's planning and discussion, the restaurant of the study subject is expected to open in northern Taiwan at the end of 2019, hoping to successfully develop a different business model to help non-profit organizations to conduct diversified operations.

\section{Analysis of Case Study}

\subsection{Business Model Analysis of the Case Study}

1) "Commodity supply business model":

This model was still guided by "skill training" and "career guidance". Hence, in operation, the balance of financial indicators was less considered, and even profits were not expected. In terms study and analysis, as for the study subject, this model mainly focused on the extension of the "methods in social work services", and expected the supported targets could learn skills through this model to achieve the goal of self-reliance and poverty reduction, with no nature of business model.

2) "Cooperative store operation business model":

This is fairly close to the typical business model in nature. In addition to the supports and assistance from the headquarters of FamilyMart in strategic planning, brand marketing and supply chains, the organization has developed its own experience and specialized knowledge in cash flow, customer reception and personnel management. Hence, in terms study and analysis, it can be classified as a type of "business model", which is greatly helpful to the study subject in the accumulation of business knowledge and operation experience.

3) "Self-catering service business model":

At the early stage of planning, this model stipulated the two cores of "profitable type" and "replicable type". "Profitable type" represents that the restaurant is expected to be self-sufficient in financial indicators and to make profits in the future, and such expectations are the main reason why many non-profit organizations transform to social enterprises. However, in the core indicators of "replicable type", its uniqueness indicates that the study object hopes to expand the business model of the restaurant across the country, which also conforms to the scale of its non-profit organization. This model is based on business thinking from the beginning idea and the planning, not only considering financial indicators but also planning for future business strategies. Therefore, in terms of study and analysis, it has all characteristics of the business model.

\subsection{Distribution Method of Earnings of Social Enterprise}

In terms of the purpose to promote social enterprise model, the research case regards it as the tool and strategy to assist the supported families to get rid of and keep away from poverty. Therefore, all the participating parents or adolescent of supported families are employed by social enterprise system by means of receiving a salary. And the earned earnings are actually invested into the related development of social enterprise model. It can be roughly divided into 3 aspects as below:

1) Continuous maintaining of the operation of social enterprise system:

Most operational earnings of social enterprise are invested into the operational work continuously, such as purchase of raw materials, salary of employees, payment of water and electricity and rent, expansion of various hardware equipment, etc. In addition to the relevant expenditure self collected by research case for support, the income of earnings has also become the important key for the social enterprise model to realize independent and sustainable development in the future.

2) $R \& D$, innovation and expansion of social enterprise program:

In addition to maintaining the operation, some earnings are also used for research and development to innovate and develop other social enterprise models, such as employees' on-the-job training, scaling up the operation, increasing the employees, developing new products and service, improving product delicacy and competitiveness, etc. 
3) Feedback to society: from the helpee to helper:

The rest earnings are used for other poverty elimination programs. As for the feedback method in this part, it is often open to all the participants to discuss the feedback method together. When the earnings are used to feed back to society, it can make the helpees have the ability to help others. In addition to increasing the confidence of helpees, it can also make the operation of social enterprise produce virtuous cycle.

\subsection{Study and Analysis of Organizational Transformation}

About the analysis on organizations transforming to social enterprises and developing business models, this study finds that non-profit organizations not only must respond to the rapidly changing the external environment but also are related to the extension of internal factors such as social work services. Hence, the following two points can be classified into for explanation: "independent financial need" and "service pattern change".

1) Demand for financial autonomy:

Under the drastic change of external environment and resource competition, when NPOs choose to provide service program, it is bound to face the economic benefit evaluation of various service models. Therefore, as for NPOs, social enterprise model can use the commercial activity and profiting means to reduce financial pressure, so that the social enterprise model can increase the financial autonomy during the process of operation and reduce NPO's crowding out effect of financial resource in this service model. Thus, the organizations can face various service models in a more elastic way.

2) Reformation of service model:

Through the observation in the case study, it can be found that the transformation of NPO into social enterprise model is not merely caused by the demand for "financial autonomy". On the other hand, for the purpose of particularity of service purpose and object, the traditional residual model social welfare service model (residual model or paternalism) in the past will be reformed where the business model is imported and "commercial profiting behavior" is used to intensify service user's learning and change their motive, so as to improve the benefits of service model program.

\section{Conclusion}

Lastly, up to this day, the development of Taiwan's NPOs has become an indispensable link in the society. Therefore, the operating management and future development of NPOs has also become the quite important issues. It is observed from the perspective of economy that most Taiwan's NPOs belong to small-scale pattern and they often cannot realize the self-sufficiency in operating management and resource collection and they have to rely on the government, enterprise or social donations for survival. In the dimension of operation, the uncertainty in finance causes the NPOs to reserve something during the target and business setting, affecting the organizational mission and development. In the dimension of human resources, due to the uncertainty in finance and operation, the organizations are often faced with the dilemma of employee turnover, affecting the setting and promotion of human resource strategy. In the end, it can be known that the development of Taiwan's NPOs will certainly face the challenges in reformation and transformation in the future and the social enterprise model can provide a new way out to NPOs.

\section{References}

Alter, K. (2007). Social Enterprise Typology [Electronic Version]. Retrieved October 1, 2017, from https://www.site.virtueventures.com/

Anheier, H. K. (2005). Nonprofit Organizations: Theory, Management, Policy. London \& New York: Routledge.

Chang, M. Y. (Ed.). (2000). NPO, Taipei: Commonwealth Publishing: Selection of Harvard Business Review.

Cheng, S. F. (2007). Conceptual Analysis of Social Enterprise. Research Journal of Institute of Public Administration and Policy, University Of South China, 8, 65-108.

Chu, J. J. (trans). (2000). Social Research Method: Qualitative and Quantitative Orientation. Taipei: Yang-Chih Book.

Feng, Y. (2000). Definition, Function and Development of NPOs. In Hsiao, H. H. (Ed.), Non-profit Sector: Organization and Operation (pp. 1-42). Taipei: Chuliu Culture.

Gann, N. (1996). Managing Change in Voluntary Organizations: A Guide to Practice. Buckingham, Philadephia: Open University Press. 
Hafford-Letchfield, T. (2006). Management and Organizations in Social Work. East Exeter: Learning Matter.

Hsiao, H. H. (Ed.). (2000). Non-profit Sector: Organization and Operation. Taipei: Chuliu Culture.

Jiang, M. S. (2002). Non-profit Management. Taipei: Best-wise Publishing.

Jiang, M. S. (2004). Enterprise-type NPO (In Review). Taipei: Best-wise Publishing.

Jiang, M. S. (Ed.). (1999). The Third Sector: Operating Management and Social Participation, Taipei: Best-wise Publishing.

Kuan, Y. Y. (2000). NPO and Social Welfare, Taipei: Yatai Books.

Kuan, Y. Y. (2002). Research into the Third Sector: Inspection of Economic Viewpoint and Interdepartmental Interaction Theory. Taiwan Social Welfare Journal (electronic journal), 3, 1-28.

Kuan, Y. Y. (2007). Development of Social Enterprise Organization in Taiwan. Chinese Non-profit Review, 1, 146-181.

Kuan, Y. Y. (2003). Development of Taiwan's Foundation under Social Change (1st ed.). Taipei: Hong's Foundation.

Larry, E. G. (1972). Evolution and Revolution as Organizations Grow. Harvard Business Review.

Lu, C. H. (2008). Social Enterprise and Entrepreneurship: Meaning and Review. The NCCU Journal of Sociology, 39, 81-112.

OECD. (1999). Social Enterprises. OECD, Publication Date: 1999/11/15.

Osterwalder, A., Pigneur, Y., \& Clark, T. (2010). Business Model Generation: A Handbook For Visionaries, Game Changers, and Challengers. Strategyzer series. Hoboken, N.J.: John Wiley \& Sons.

Sargeant, A. (1999). Marketing Management for Nonprofit Organizations. Oxford and New York: Oxford University Press.

Situ, D. H. (1999). Operating Management of NPO. Taipei: Commonwealth Publishing.

Sun, P. H., Liao, C. F., \& Tung, K. K. (Ed.). (2001). Strategic Management of NPOs, Taipei: Hungyeh Culture.

Wolf, T. (1990). Managing a Nonprofit Organization. N.Y.: Prentice-Hall Press.

Yu, P. S. (trans). (2004). Peter Drucker: Mission and Leadership—Learn the Management Method from NPOs. Taipei: Yuan-Liou Publishing.

\section{Copyrights}

Copyright for this article is retained by the author(s), with first publication rights granted to the journal.

This is an open-access article distributed under the terms and conditions of the Creative Commons Attribution license (http://creativecommons.org/licenses/by/4.0/). 